\title{
Ciência e política das drogas: as controvérsias em torno das políticas públicas de internação compulsória
}

\section{Science and drug policies: controversies in public policies of compulsory confinement}

\section{Ciencia y política de drogas: las controversias alrededor de las políticas públicas de internación compulsiva}

\author{
Alexandre Kerr Pontes* \\ Universidade Federal do Rio de Janeiro - UFRJ, Rio de Janeiro, Rio de Janeiro, Brasil \\ Ana Paula Santos Meza** \\ Universidade Federal do Rio de J aneiro - UFRJ, Rio de Janeiro, Rio de Janeiro, Brasil \\ Pedro Paulo Gastalho de Bicalho*** \\ Universidade Federal do Rio de Janeiro - UFRJ, Rio de Janeiro, Rio de Janeiro, Brasil
}

\begin{abstract}
RESUMO
Propõe-se, no âmbito deste trabalho, problematizar a discussão acerca das internações compulsórias, a partir de apontamentos para as controvérsias que têm habitado as propostas de políticas públicas contemporâneas, as quais emergem da temática das drogas no Brasil. Entende-se que tal debate converge para o plano da articulação entre ciência, sociedade e tecnologia, composição de forças heterogêneas que produzem o que se toma por realidade. Em meio a tais controvérsias, propomos, com base na Teoria Ator-Rede, traçar uma cartografia das redes que fazem circular e acabam por produzir aquilo que entendemos por internações compulsórias. As controvérsias rastreadas nos conduziram a uma relação indissociável entre a construção de verdades e a produção política. Os modos de conhecer - e a consequente produção de saberes - produzem mundos que compõem territórios existenciais na contemporaneidade: ontologias que se constituem a partir do caráter performativo das práticas sociais.
\end{abstract}

Palavras-chave: drogas, ciência, políticas públicas, controvérsias, internação compulsória.

\footnotetext{
ABSTRACT

In this article we problematize the ongoing discussion around the public policies of compulsory confinement for drug users that is happening in Brazil, as well as the controversies that emerge from the public debate on drugs and the implementation of these policies. We understand that the articulation between the heterogeneous forces of science, society and technology produce the social understanding of the issues around the thematic of drug use. In that sense, we assert that there is an inseparable
} 
relation between knowledge and politics: the act of producing truths - and the consequent production of knowledge - creates worlds that constitute contemporary existential territories: ontologies that are composed from the performative character of social practices. Amid such controversies, our proposal is, based on Actor Network Theory, to draw a map of networks that produce what we understand as compulsory confinement. These controversies led to a strong connection between the heterogeneous forces of science, society and technology produce the social understanding of the issues around the thematic of drug use. In that sense, we assert that there is an inseparable relation between knowledge and politics: the act of producing truths - and the consequent production of knowledge - creates worlds that constitute contemporary existential territories: ontologies that are composed from the performative character of social practices.

Key-words: drugs, science, public policies, controversies, compulsory confinement.

\section{RESUMEN}

Se propone, en el marco de este trabajo, problematizar la discusión de la internación compulsiva a partir de las notas de las controversias que han conformado las propuestas de políticas públicas contemporáneas que se desprenden del tema que involucra la cuestión de drogas en Brasil. Por lo tanto, se entiende que tal debate converge hacia el plano de la articulación entre la ciencia, la sociedad y la tecnología, la composición de fuerzas heterogéneas que producen lo que se entiende por realidad. En medio de tales controversias, se propone, sobre la base de la teoría del actor-red, dibujar un mapa de las redes que circulan y terminan produciendo lo que entendemos por internación compulsiva. La controversia nos llevó a un vínculo indisoluble entre la construcción de verdades y producción política: los modos de conocer - y la consiguiente producción de saberes - producen mundos que componen territorios existenciales en la contemporaneidad: ontologías que se constituyen a partir del carácter performativo de las prácticas sociales.

Palabras clave: drogas, ciencia, políticas públicas, controversias, internación compulsiva.

\section{Introdução}

As discussões contemporâneas sobre drogas no Brasil apontam um laço inextrincável entre epistemologia e política: os modos de conhecer engendram realidade e produzem mundos, constituindo um assunto de discussão constante feito por diversos saberes acadêmicos, veículos da mídia, políticas públicas, além de perpassar os diálogos em espaços cotidianos de vivência.

Discutir tal assunto implica, primeiro, considerá-lo a partir de sua complexidade própria, direcionando o debate no campo múltiplo em que o "problema das drogas" situa-se. Nomeada a questão de tal forma, pode-se vislumbrar o caráter problemático que este tema apresenta, seja dos então considerados pontos de vista social ou acadêmico. Questão colocada, portanto, à atividade da pesquisa 
como uma ciência em ação. Aqui, uma "Psicologia em Ação" (Moraes, 1998).

Pesquisar é também evidenciar as relações políticas, econômicas, sociais e institucionais, o lugar que se ocupa enquanto pesquisador e as relações de poder em jogo que compõem os 'resultados' da pesquisa, mesmo que estas sejam usualmente objeto de desejo de neutralização. Como aponta Foucault (1994) é também, entre outras coisas, estar comprometido com sua atualidade: "E o que é esse "agora" no interior do qual estamos, uns e outros, e que define o momento onde escrevo?" (p. 679). E continuamos com ele quando prossegue afirmando:

“(...) trata-se de mostrar em que e como aquele que fala enquanto pensador, enquanto cientista, enquanto filósofo, ele mesmo faz parte desse processo e (mais que isso) como ele tem um certo papel a desempenhar neste processo, no qual ele então se encontra, ao mesmo tempo, como elemento e ator." (p. 680).

Podemos também manter em análise os efeitos que se produzem enquanto escrita/prática como problematização de uma atualidade e como interrogação para o que escreve "dessa atualidade da qual faz parte e em relação à qual tem que se situar (...)" (Foucault, 1994, p. 681). Segundo Foucault (1994) isso "poderia caracterizar a filosofia como discurso da modernidade e sobre a modernidade. Qual é esta minha atualidade? Qual é sentido desta atualidade? E o que faço quando falo desta atualidade?" (idem). Atualidade produtora de mundos, de controvérsias, de caixas-preta.

Conforme Hüning (2008) o conteúdo da caixa-preta ${ }^{1}$ de um trabalho de pesquisa concerne a este processo que desde o princípio começa a configurar as condições de possibilidade, marcando estratégias, forças, linguagens, que acompanham a fabricação de um fato ou artefato no mundo científico. Uma opção teórica e política:

“(...) mostrando pelo menos um pouco do que contém sua caixa-preta, algumas trajetórias percorridas, processos, encontros, relações que se estabeleceram... Muitos diriam que isso seria apenas um preâmbulo, (se) necessário para 'contextualizar' o leitor no 'trabalho científico' (...) absolutamente descartável quando os 'resultados da pesquisa' migrarem - se migrarem - para as instâncias oficiais da Ciência (...) não estou fazendo um preâmbulo. Não escrevo aqui apenas uma 'introdução' para 'situar' o leitor ou adiantar o que virá. Aqui começa a fabricação e escrita de minha tese. E começa pela inevitável conclusão de que para que eu consiga escrever minha tese, é necessário falar de minha experiência e 
'discutir a relação', sem pretender com isso um apelo ao subjetivismo, ou qualquer tentativa de tornar mais 'transparente' minha escrita, à luz de minha 'história pessoal', ou mostrando 'minha interferência' em relação do 'objeto' estudado. (...) inclui perguntar quem é o pesquisador, em que rede de relações ele se insere, qual sua posição moral e política, que valores e condições marcam os meios de produção do conhecimento. Isso implica não apenas falar sobre mim, mas deixar falar os outros elementos que compõem as condições de produção da pesquisa, analisar as condições culturais e políticas que constituem o que é possível pensarmos e por onde é possível nos mover, em contrapartida à ilusão de 'livre escolha' e da produção de relatos neutros e objetivos sobre o mundo." (2008, p. 18-19, grifos da autora).

A perspectiva política da pesquisa e do conhecimento encontra potentes pontos de articulação com uma ciência definida, a partir de sua articulação com a rede de atores. Não se trata de ignorar as diferenças, nem tratá-las como se fossem uma mesma diretriz. Pesquisar é também, dar voz/letra aos outros da pesquisa, 'polifonar', evidenciando o processo coletivo e heterogêneo que constitui a pesquisa, e não centrado na figura neutra e asséptica do cientista que elucida verdades supostamente descobertas na natureza. Polifonar, inclusive, nossas referências. Fazer reverberar Foucault e Latour, produzindo não somente uma rede de atores, mas, sobretudo uma "rede de autores". Diferente de uma herança mais tradicional da ciência ainda focada na revelação de ditas verdades, em busca de resultados que revelariam essências dos objetos/fenômenos, o foco em questão aqui se constitui em outro. Não na ciência 'pronta', mas na 'feitura', na sua confecção, no processo de construção da ciência, do verdadeiro, como nos afirma Latour (2000) o foco é na "ciência em ação".

E podemos também seguir as pistas de Foucault cujos pensamentos apontam numa direção convergente. Segundo Oksala (2011):

"O impacto crítico da filosofia de Foucault não se baseia nos julgamentos explícitos que ele faz, mas na abordagem que adotou para analisar nossa cultura. Enquanto a ciência e grande parte da filosofia pretendem decifrar, em meio à fusão de eventos e experiências, aquilo que é necessário e pode ser enunciado como universal, o pensamento de Foucault move-se na direção oposta. Ele tentou encontrar, entre o que era considerado da ordem da necessidade, aquilo que, a um exame filosófico mais detalhado, revelava-se contingente, fugaz e arbitrário. Para Foucault, o objetivo da filosofia é questionar o modo como pensamos, vivemos e nos relacionamos com outras 
pessoas e com nós mesmos no intuito de mostrar que aquiloque-é poderia ser diferente." (p.16).

Desmontar e desacomodar o lugar clássico de pesquisador e pesquisa é subverter o oferecimento de verdades, é percorrer a emergência de discursos controversos. Aqui, sobre o cenário das políticas públicas de drogas, explorando como esses regimes de verdade se constituem, produzindo subjetivações e sentidos como A verdade, O científico.

Muitas são as demandas por políticas de enfrentamento às drogas haja vista seu naturalizado status de "problema social" - reificando uma lógica de guerra presente em documentos oficiais, como o plano "Crack, é possível vencer", lançado pelo Governo Federal em dezembro de 2011. Políticas produzidas em diferentes estratos, dos quais se sobressaem o foco sobre o tráfico de um lado, e o dependente químico de outro. Do ponto de vista acadêmico, por sua vez, pode-se abordar este mesmo tema a partir de uma abordagem neurológica, tentando descobrir como algumas substâncias afetam os neurotransmissores (Focchi, Leite \& Scivoletto, 2001), ou pode-se estudar o tráfico e as relações constituídas por este sob um olhar sociológico (Misse, 2007) ou, ainda, por ontologias que se constituem a partir do caráter performativo das práticas sociais (Barbosa \& Bicalho, 2013) além de outras possíveis formas de se abordar este campo tão prolífico.

\section{A Rede de atores e as controvérsias: uma questão de método}

Com a noção de rede de atores, Latour (1994) aponta para o caráter heterogêneo da atividade científica. Enquanto na perspectiva epistemológica essa atividade era definida com base em sua produção conceitual e teórica, na análise de Latour ela é enunciada a partir das conexões estabelecidas entre atores heterogêneos, entre humanos e não-humanos. Não há nenhum princípio capaz de estabelecer, de antemão, quais serão mobilizados para a construção de uma rede; ao contrário, uma rede de atores se define por engendrar conexões performativas que, uma vez estabelecidas, dotam de propriedades novas aqueles nelas implicados (Moraes, 2004). Conexões, assim, que performam práticas sociais.

Meyer (2009) argumenta que enquanto o jeito "frio" de expor a ciência é através de objetos estabilizados, o jeito "quente" trabalha através de relacionalidade, isto é, lançando luz nas múltiplas relações entre sujeitos e objetos, e entre as posições dos vários atores numa controvérsia, a qual foca em posições, relações e processos, mais do que em produtos e objetos estáveis. Aqui os objetos encontram-se abertos em vários sentidos: na flexibilidade de interpretações, no 
envolvimento que as pessoas têm com eles, na suscetibilidade para serem questionados.

Assim, explorar as controvérsias pode desestabilizar os nossos centros de produção de verdade, ressaltando o caráter produtivo no processo em que são forjados os enunciados ditos verdadeiros.

Os que estudam ciência pela perspectiva das ciências sociais - uma separação artificial que emerge na tentativa de dividir natureza e sociedade - têm observado que a ciência é pelo menos tão rica em discordância e incerteza quanto é na harmonia estabelecida pelo consenso. Posicionando a ciência em seu contexto social, cultural e político ela aparece muito mais aberta a conflitos e desacordo:

"Concentrando-se em ciência nas suas relações com cada um deles (reinos sociais) quase inevitavelmente introduz elementos de controvérsia. Pois, assim, deixa de ser simplesmente uma questão de como o mundo físico funciona, e em vez disso se torna uma questão de como grupos de pessoas se relacionam entre si - colegas e rivais, patrocinadores e governadores, jornalistas, críticos e políticos, etc." (Meyer, 2009, p.2).

E por que estudar os tópicos quentes, como as controvérsias? O que de potente essa abordagem pode proporcionar? Aposta-se que é no curso de disputas que os interesses especiais, as preocupações vitais e os pressupostos ocultos de diversos atores são revelados. Ao trazer estes discursos controversos à vista do público, os pressupostos que são normalmente implícitos são desafiados, os procedimentos de rotina são analisados, e os argumentos são atacados. O estudo das controvérsias faz manifestar o processo que guia ao conhecimento científico e ao artefato tecnológico, aborda o processo em sua abertura ainda. "As controvérsias revelam, em outras palavras, a fábrica política e social da ciência." (Meyer, 2009, p. 3). Visibilizam as várias políticas de confecção de cientistas e não cientistas questionando as práticas de purificação que deixaram os trabalhos da ciência pautados em separações e que conferem legitimidade a apenas alguns discursos de alguns enunciadores.

Deveríamos entender as drogas por suas propriedades químicas, ou pelos seus efeitos de eliminação de doenças e aprofundamento de sofrimentos, ou pelas relações econômicas de sua produção e comercialização? Não seria a droga conformada por todos estes elementos? Pode-se, então, conceber a droga como um objeto híbrido (Latour, 1994), ou seja, não pertencente exclusivamente a qualquer domínio de saber: não é um objeto que essencialmente pertenceria à química, à medicina, às neurociências, ou de um outro lado, à antropologia, à psicologia, como é comumente separado os saberes entre naturais e humanos. Seguindo os passos de Vargas (2008), pode-se considerar a droga como um objeto sócio-técnico. 
[...] essas matérias moleculares constituem objetos sóciotécnicos que, embora sempre possam ser distinguidos conforme as modalidades de uso (matar, tratar, alimentar, por exemplo), não comportam diferenças intrínsecas absolutas ou essenciais, mas sempre e somente diferenças relacionais. Pois sucede às drogas (e aos medicamentos e alimentos) o mesmo que às armas (e às ferramentas): tais objetos sócio-técnicos permanecem integralmente indeterminados até que sejam reportados aos agenciamentos que os constituem enquanto tais. (Vargas, 2008, p. 41).

Esta perspectiva se aproxima da proposição de Latour (1994), na medida em que propõe que as drogas possuem sua agência não apenas por suas propriedades naturais ou, por exemplo, pelas relações econômicas em torno dela, mas, também, pelos conjuntos de redes sócio-técnicas que a colocam como objeto de análise e a definem a partir destes saberes e práticas; ou seja, a droga é, ao mesmo tempo, um objeto de disputa econômica, política, médica, em resumo: um objeto híbrido. Assim, caberia indagar: que agenciamentos são esses? Como compreender as engrenagens que movimentam as variações de sentido que há sobre a droga? Sendo este um assunto complexo, por onde se deveria começar? Esta pergunta pode ser respondida utilizando-se do conceito de rizoma proposto por Deleuze e Guattari (1995), na medida em que se entende que agenciamentos funcionam de forma rizomática. Sem pressupor uma centralidade essencial de qualquer um destes discursos pode-se então começar de qualquer ponto e, a partir dele, trilhar os diferentes caminhos que forem sendo cruzados, sem qualquer expectativa de encontrar uma verdade ao fim, mas desvendar os múltiplos cruzamentos de elementos heterogêneos; dando, a cada passo, um novo corpo à investigação. "Um rizoma não começa nem conclui, ele se encontra sempre no meio, entre as coisas, inter-ser, intermezzo" (idem, p. 37).

Em alguns estados brasileiros - sobretudo São Paulo, Rio de Janeiro e Minas Gerais - foi iniciada, em 2012, uma política de internação compulsória para usuários de drogas, com destaque para o crack. Esta prática tem sido bastante polêmica e tem chamado diferentes atores sociais para discutir este princípio desde sua legalidade até questões de escopo ético. Tomando este ponto como de partida para as indagações que seguirão, começa-se a delimitar com maior clareza as questões que interessam para este trabalho.

Aborda-se o atual objeto a partir da ideia de controvérsia, proposta por Latour (2008). Colocar em análise como as controvérsias irrompem, chegam a um fim e o processo através do qual isso acontece significa perseguir as pistas de sua emergência e de seu 
fechamento, os caminhos pelos quais são tecidas as redes sociais, os fatos e artefatos científicos. O fechamento de uma controvérsia significa que uma verdade ganhou e os argumentos em seu favor retrospectivamente se tornam aqueles que são razoáveis (Mol, 2007) e não que ela é mais racional ou verdadeira que as outras que esmoreceram pelo caminho. O objetivo é desafiar as grandes categorias que organizam o mundo contemporâneo problematizando os modos de produção da realidade e potencializar construções mais polifônicas, mais articuladas, um multiverso - já que universal só é possível com políticas que defendem uma suposta natureza.

Assim as controvérsias são uma rachadura que abre a possibilidade dos enunciados serem interpelados, serem contraditos, abre espaço para a recalcitrância, para que algo de diferente seja dito, a produção de desvio do já posto.

A relevância de se debruçar sobre a questão a partir deste posicionamento está na possibilidade de conceber a própria internação compulsória e suas consequências como um campo problemático indefinido. Isto quer dizer que, ainda que haja uma diversidade de discursos políticos e científicos em torno desta temática, ela está longe de se tornar um assunto encerrado, uma caixa preta, como diria Latour (2000). A postura adotada permite uma abertura para o surgimento de questionamentos sobre a própria internação: seus efeitos subjetivos e materiais.

Analisa-se a questão das internações compulsórias a partir dos discursos que serviram para produzi-la como uma demanda. Com isto, demonstramos as controvérsias presentes no debate em torno da política pública de internação compulsória que está em processo de construção no Rio de Janeiro. Embora a demarcação da cidade do Rio de Janeiro tenha sido o propulsor inicial para abordar a questão, o uso de documentos que extrapolam uma territorialidade vinculada a uma cidade se faz necessário metodologicamente. Seguindo diversas pistas, fez-se uso de documentos oficiais que foram produzidos por diversas instituições para produzir a emergência dos aspectos relevantes destes embates e, assim, demonstrar a vivacidade destas construções e seus efeitos. Desta forma, os agentes participantes se tornarão evidentes, assim como seus posicionamentos e estratégias em busca de construir uma verdade científica a respeito do tema das drogas e dos efeitos das políticas públicas.

\section{Seguindo cientistas em ação}

Latour (2000) propõe uma forma interessante de observar a ciência: a partir de seu processo de construção. Um assunto se torna fato quando as controvérsias sobre ele se encerram e, consequentemente, para os cientistas, o fato se torna o motivo pelo qual as controvérsias 
se encerram. Dito de outra forma, enquanto ainda subsiste mais de uma perspectiva sobre um determinado objeto da ciência, a controvérsia está viva e, portanto, cientistas trabalham ininterruptamente para encerrá-la e colocar um ponto final na questão. A partir do momento em que um determinado saber sobre um objeto ganha destaque e apoio da comunidade científica, sua força passa a ser suficiente para encerrar uma questão, transformando este assunto em uma caixa preta. Latour toma o termo "caixa preta" a partir da cibernética, cuja utilização se dá quando um conjunto de comandos é complexo demais e, em seu lugar, é desenhada uma caixa preta, importando somente o que entra e o que sai da caixa. Esta metáfora é utilizada para designar aquilo que na ciência se tornou uma caixa preta, ou seja, um assunto encerrado que é tomado como fato e, portanto, o que importa dele são seus efeitos, o que dele deriva. A ciência seria um conjunto de "caixas pretas" que por vezes se apoiam uma nas outras. Assim, no momento que algo se torna uma "caixa preta" os cientistas passam a atribuir o encerramento da controvérsia à própria evidência dos fatos, como se o encerramento fosse derivado do saber que se construiu sobre determinado objeto. O saber se reifica reforçando a caixa preta.

A sugestão de Latour (2000) é observar a ciência em seu processo de construção. Sua proposta busca compreender os processos através dos quais uma controvérsia se mantém ou desaparece. Para tanto, o autor sugere seguir a ciência em ação, ou seja, observar como os cientistas procedem para construir os seus saberes e que tipos de controvérsias emergem para transformarem suas construções em caixas pretas. Seguindo estes passos, o presente trabalho se propõe a lançar luz sobre as controvérsias em torno das internações compulsórias. Como primeiro passo, iniciaremos uma exposição dos atores observados nesta análise.

O primeiro fator que influenciou a escolha dos atores a serem seguidos foi o processo de habitação do campo. Com isso, afirma-se que boa parte da investigação foi formulada a partir da incursão dentro do tema, partindo-se de diversos pontos de entrada. A participação em seminários e debates, matérias jornalísticas que propagam determinados vieses sobre as drogas em geral e o crack em particular, livros e artigos acadêmicos que versam sobre o assunto, são exemplos do material que compôs a problematização inicial e o direcionamento argumentativo e investigativo da atual pesquisa.. Seguindo as trilhas que nos foram sendo colocadas na medida em que buscávamos entender melhor a controvérsia em torno das internações compulsórias, encontramos instituições, cientistas e políticos que tentavam colocar a sua verdade em evidência com diferentes regimes de saberes, aliados humanos e não-humanos. Como segundo fator, a facilidade de encontrar 
produções destes atores em torno da temática facilitou a coleta de informações.

Além disso, entendemos que as visões aqui analisadas focam nos argumentos presentes na controvérsia em geral presenciadas nos momentos de aprofundamento do campo de investigação. Desta forma, deve-se pontuar que as versões abordadas não abordam uma dimensão quantitativa das diferentes opiniões dentro do assunto nem suas diversas variações. Os documentos aqui analisados foram estrategicamente utilizados a partir de um aprofundamento amplo do campo problemático e está longe de esgotá-lo. Servem como exemplos paradigmáticos de determinadas categorias de pensamento que rondam a temática abordada. Com o conceito de exemplo paradigmático entendemos que estes documentos formulam alguns princípios de uma mesma racionalidade técnico-política e, portanto, servem como exemplos desta racionalidade e de seus modos de construção. Trata-se de uma eleição baseada em uma série de explorações e aproximações com o tema.

\section{Quem está presente na controvérsia?}

Alguns atores foram privilegiados para analisar a presente controvérsia. Foram utilizados dois projetos de lei, o PL 7.663 do senador Osmar Terra e o PLS 111/10 do senador Demóstenes Torres, ambos tramitando nas comissões do Senado Federal e que buscam alterar a lei 11.343 de 2006 , que rege a atual política de drogas no Brasil. A escolha destes dois projetos está relacionada com a construção da justificativa para a alteração da lei, que traz os fundamentos para aportar tais modificações. Estes projetos foram extremamente citados por aqueles que se opõem à internação compulsória dentro do campo aqui analisado, o que aprofunda a relevância de sua escolha para discussão, já que estes documentos podem ser considerados "quentes", ou seja, estão em debate e não se tornaram caixas pretas, sendo extremamente importantes para a análise das controvérsias. Em seguida, foram procuradas documentações que seguissem na linha contrária dos senadores, mesmo que indiretamente, e que buscassem argumentos diferentes dos projetos mencionados. Assim, foram eleitos uma coletânea de matérias jornalísticas e documentos digitais para lançar luz sobre algumas controvérsias. No presente trabalho, foram discutidas diferentes controvérsias que estão extremamente imbricadas, mas que, por motivos de organização textual, foram divididas em tópicos. Como último ponto de construção desta análise está a revisão bibliográfica que forneceu os elementos necessários para elaborar alguns elementos da controvérsia, principalmente no quesito que se refere ao estatuto médico da dependência química. O Manual de 
Diagnósticos Psiquiátricos é uma ferramenta extremamente utilizada na formulação e proposição de categorias diagnósticas e, como tal, tem grande impacto nas práticas médicas atuais.

\section{Controvérsia 1 - Epidemia}

O primeiro ponto da controvérsia em questão é o que chamaremos de "epidemia do crack". Este ponto é essencial para entender os contornos do problema e a origem da controvérsia. Apontamos que a existência de um argumento sobre uma possível epidemia do uso do crack é o cerne da questão da internação compulsória no momento político atual. Os atores sociais que visam implementar uma política de internação buscam convencer seus pares sobre a existência de um problema social que necessitaria uma solução enérgica. Como exemplificação desta trajetória argumentativa, deixamos em evidência o discurso presente no PLS 111/10.

Nas entrevistas com estudiosos do assunto, usuários e seus familiares, constata-se uma peste espalhada pelos quatro cantos do país, o crack. Além da velocidade com que vai do cachimbo ao cérebro, a substância também chega rapidamente às ruas. A mistura de cocaína em pó com bicarbonato só caiu em um item, o preço. Uma pedra de crack era vendida por 10 reais e foi baixando até se ter notícia de ela estar por 1 real ou até 50 centavos. Inclusive, se diz que a moedinha entregue a um mendigo é suficiente para ele adquirir a droga. Mas é anacrônico o estereótipo do usuário de crack ser alguém maltrapilho que pede esmola. $O$ crack se socializou: é consumido por quem mora em pontes com a mesma intensidade de quem reside em mansões. Crianças em situação de rua, que antes cheiravam cola de sapateiro e esmalte, aderiram ao crack. O mesmo fizeram jovens insuspeitos, de família estabilizada e vida confortável. Cocainômanos igualmente passaram a fumar o subproduto do pó. Além do fator econômico, o crack atrai tanta gente pelos efeitos.

O ponto principal do argumento deste projeto é convencer que há uma epidemia do crack e oferecer algumas soluções alterando a atual lei de drogas no país. Dentro de algumas das propostas de solução se encontra a internação compulsória. Porém, é interessante denotar os vários ataques ao argumento da existência de uma epidemia. O mais interessante a ser exemplificado está contido em matéria publicada no portal eletrônico do G1 que questiona a tomada de iniciativa do governo federal de implementar um programa de combate ao crack partindo da premissa de que existe um problema antes mesmo de sua confirmação com base em estudos. "Apesar de admitir que 
considera a droga uma "epidemia" no país, o governo reconhece que não sabe o perfil dos usuários nem onde eles estão nem qual é a melhor forma de tratá-los" ${ }^{2}$. O título da matéria já deixa evidente a controvérsia "Governo libera R\$ 738 milhões sem conhecer 'epidemia' de crack". (Idem) O que está em questão não é a contestação de uma epidemia, mas a tomada de atitude antes mesmo de diagnosticar a existência ou não de tal epidemia. Para resumir a controvérsia temos, de um lado, um argumento sobre a existência de um problema social que cresce em níveis alarmantes, de outro, contesta-se a existência de dados que possam comprovadamente atestar a existência de um problema. Mas qual seria a relação da epidemia com a internação compulsória?

Hartman e Gollub, em 1999, analisaram reportagens publicadas em jornais americanos sobre a "epidemia do crack" e concluíram que estas eram sensacionalistas, pois não tinham embasamento científico e teriam ocasionado um desvio de foco das autoridades sobre outros problemas sociais mais relevantes. A controvérsia, deste modo, parece não se restringir ao território nacional.

Vale salientar que até o momento da confecção deste artigo, não foi encontrado qualquer material científico que tivesse como foco central a investigação da questão da epidemia do crack no Brasil. Não obstante, concomitante à elaboração do artigo, encontra-se em vias de publicação o relatório intitulado "Pesquisa Nacional sobre o Uso do Crack", resultado de investigações epidemiológicas realizadas pela Fundação Oswaldo Cruz (FIOCRUZ) por encomenda da Secretaria Nacional de Políticas sobre Drogas - SENAD.

Controvérsia 2 - capacidade de autodeterminação

Chega-se ao segundo ponto importante da controvérsia em torno da internação compulsória: a afirmativa de que há uma epidemia que se conjuga com o argumento de que usuários de crack não são capazes de promover autonomia de cuidado e, portanto, precisam de tratamento compulsório. Segundo reportagem do portal Terra, o prefeito do Rio de Janeiro Eduardo Paes afirma que "Está muito claro que os dependentes dessa droga crack não conseguem tomar decisões. Por isso, vamos intensificar o trabalho da prefeitura contra o crack" ${ }^{3}$. Este ponto é essencial para entender a perspectiva dos defensores de uma política de internação compulsória. Para entender melhor esta relação, é preciso atentar para a Lei 10.216/01 - que “Dispõe sobre a proteção e os direitos das pessoas portadoras de transtornos mentais e redireciona o modelo assistencial em saúde mental". Esta Lei visa a regulamentar a assistência a pessoas em sofrimento psíquico garantindo alguns direitos básicos para impedir violações. Nela está contido regimento necessário para a internação compulsória de pessoas com problemas de saúde mental. Neste 
trabalho, o importante para se analisar é a relação que tem sido construída entre dependência química e saúde mental. Sob que aspectos a dependência química se tornou um problema médicopsiquiátrico? Segundo Carneiro (2005), um dos primeiros médicos a definir o uso de drogas como uma doença, Benjamin Rush, se referiu ao problema do uso de drogas como uma "paralisia da vontade". Neste quesito, podemos antever uma continuidade com o presente naquilo que define a dependência química como doença: uma doença da vontade, da incapacidade de autodeterminação.

Critérios para Dependência de Substância (DSV-IV) Um padrão mal-adaptativo de uso de substância, levando a prejuízo ou sofrimento clinicamente significativo, manifestado por três (ou mais) dos seguintes critérios, ocorrendo a qualquer momento no mesmo período de 12 meses:

(1) tolerância, definida por qualquer um dos seguintes aspectos:

(a) uma necessidade de quantidades progressivamente maiores da substância para adquirir a intoxicação ou efeito desejado (b) acentuada redução do efeito com o uso continuado da mesma quantidade de substância

(2) abstinência, manifestada por qualquer dos seguintes aspectos:

(a) síndrome de abstinência característica para a substância (consultar os Critérios A e B dos conjuntos de critérios para Abstinência das substâncias específicas)

(b) a mesma substância (ou uma substância estreitamente relacionada) é consumida para aliviar ou evitar sintomas de abstinência

(3) a substância é freqüentemente consumida em maiores quantidades ou por um período mais longo do que o pretendido (4) existe um desejo persistente ou esforços mal-sucedidos no sentido de reduzir ou controlar o uso da substância

(5) muito tempo é gasto em atividades necessárias para a obtenção da substância (por ex., consultas a múltiplos médicos ou fazer longas viagens de automóvel), na utilização da substância (por ex., fumar em grupo) ou na recuperação de seus efeitos

(6) importantes atividades sociais, ocupacionais ou recreativas são abandonadas ou reduzidas em virtude do uso da substância (7) o uso da substância continua, apesar da consciência de ter um problema físico ou psicológico persistente ou recorrente que tende a ser causado ou exacerbado pela substância (por ex., uso atual de cocaína, embora o indivíduo reconheça que sua depressão é induzida por ela, ou consumo continuado de 
bebidas alcoólicas, embora o indivíduo reconheça que uma úlcera piorou pelo consumo do álcool)

Especificar se:

com Dependência Fisiológica: evidências de tolerância ou abstinência (isto é, presença de Item 1 ou 2).

Sem Dependência Fisiológica: não existem evidências de tolerância ou abstinência (isto é, nem Item 1 nem Item 2 estão presentes). (DSM - IV)

Observando o item quatro do Manual de Diagnóstico e Estatístico de Transtornos Mentais IV (DSM-IV) podemos compreender que, mesmo com alguns efeitos fisiológicos atuando conjuntamente para compor 0 quadro de diagnóstico de dependência química, o aspecto subjetivo da incapacidade de controlar o uso permanece como constante na mentalidade médica atual e é um fator elementar para a construção do diagnóstico. Não somente no raciocínio médico, a percepção social de usuário de drogas, principalmente o crack, é metaforizado a partir de figuras como "zumbi". "Também é célere o tempo entre o dia em que consome a primeira pedra de crack e a constatação dos especialistas de que virou um zumbi a perambular pelas ruas $100 \%$ viciado". (PLS 111/10) Estas imagens do uso da droga servem para compor a estratégia de definir usuário de drogas como aqueles que são incapazes de controlar o próprio juízo mental e, portanto, precisam de intervenção externa, médica ou jurídica, para conter a autodegradação.

É curioso, no entanto, que dentro da própria medicina haja uma controvérsia sobre a pertinência do diagnóstico médico perante o uso de drogas. Apesar da medicina ter se ocupado e tomado para sua jurisdição o uso de substância psicotrópicas, não foi sem contestação ou resistência que este projeto foi realizado. Segundo Conrad (2007), um dos principais fatores que contribuiu para a medicalização da dependência química foi a própria militância de usuários, principalmente o grupo de Alcoólicos Anônimos, pois com um novo estatuto de doença, houve também uma mitigação da responsabilidade do doente sobre sua própria aflição. Porém, a "ausência" de responsabilidade sobre o uso de drogas ainda é matéria de disputa. Um exemplo possível desta resistência pode ser encontrada no campo jurídico, onde o uso de substâncias químicas, em termos de jurisprudência, não é uma constante para atenuar a qualificação de um crime. Ousaríamos conjecturar que, caso a mesma diligência fosse utilizada nos casos de internação compulsória como nas sentenças criminais, a estratégia de desresponsabilizar usuários de drogas de suas ações, seria descartada de imediato. Esta afirmação baseia-se na próxima controvérsia a ser analisada: as internações compulsórias seriam uma forma de encarcerar a 
população de rua que ocupa espaços que, por vezes, são denominadas de "crackolândias".

\section{Controvérsia 3 - limpeza social}

Na coletânea de artigos "Drogas: Direitos Humanos e Laço Social" (Conselho Federal de Psicologia [CFP], 2012), uma série de autores emergem para contestar a medida de internação compulsória. Agora, não mais a partir de aspectos médicos e conceituais, mas de sua pertinência política. É recorrente a afirmação de que a internação compulsória teria um objetivo implícito: realizar a limpeza de alguns espaços urbanos. A ocupação de determinados espaços públicos têm chamado a atenção do poder público. Assim, as estratégias de internação compulsória esquadrinham um determinado tipo de usuário, aquele que ocupa os espaços públicos da cidade. Destaca-se, portanto, a crítica às atuais políticas para usuários de drogas, que não têm uma preocupação com a questão do uso abusivo e dependente de substâncias. Preocupam-se, eminentemente, com aqueles usuários que se fazer ver em seu uso através de suas ocupações urbanas. A limpeza seria, portanto, uma tática de invisibilizar estes usuários.

Um outro ponto levantado dentro desta controvérsia são as vagas para tratamento. Para atingir as metas estabelecidas de vagas para internação, o Governo Federal tem disponibilizado recursos para comunidades terapêuticas. Este fator tem gerado uma dupla controvérsia: a rede atual de atendimento a usuários que buscam o serviço voluntariamente não está estruturada. Qual seria o propósito de destinar recursos a outro tipo de tratamento que não possui uma eficácia comprovada? Estes são argumentos presentes, por exemplo, na reportagem “Dependência Química: Internação é solução? Pode-se notar que o ataque direto não é em relação ao argumento médico da autodeterminação do usuário de drogas, mas focaliza eminentemente na ineficácia do tratamento compulsório e na falta de justificativa para a efetivação da política sem eficácia comprovada.

\section{Conclusão}

É mister constatar que nem sempre as controvérsias localizam-se dentro de um mesmo plano de argumentação. Evidenciamos que nem sempre os argumentos dentro da controvérsia buscam se contradizer de uma forma lógica. O embate político não pode ser delimitado a partir de argumentos lógicos. Mais do que isso, o que geralmente define a força de um argumento é o número de aliados que este pode angariar, humanos e não-humanos. 
No campo das drogas, pode-se constatar a existência de múltiplas controvérsias que por vezes se cruzam, produzindo diálogos ou embates. Atualmente, o debate da internação compulsória continua produzindo controvérsias e, com isso, gerando novos atores sociais que buscam uma solução definitiva e o encerramento do problema, a produção de uma nova caixa preta.

Ainda que o principal argumento que respalda as leis referentes ao combate ao tráfico e uso de algumas substâncias psicoativas seja a defesa da saúde pública, os marcos legais atuais em relação às substâncias consideradas ilícitas no Brasil oferecem claras controvérsias que evidenciam políticas higienistas baseadas em ideologias que remetem a uma verdadeira guerra às drogas.

Contudo, fica uma pergunta. Tomando como base a realidade do Brasil (e, por conseguinte, de demais nações latinoamericanas), como se constroem tais processos de argumentação?

Ao analisarmos as três controvérsias aqui destacadas: o uso político da noção de epidemia, a afirmação da incapacidade de autodeterminação e a limpeza social como direito à cidade, um último aspecto merece ser destacado. As ações implementadas (inclusive na forma da lei) e os critérios apontados para a produção (e captura) dessas políticas apresentam muitas vezes discursos sobre risco e periculosidade, que torna possível o "cuidado" (e a punição) por meio de controle e vigilância, uma vez que se pauta na virtualidade do sujeito a quem tais políticas se destinam. Discursos de verdade, discursos que produzem modos de viver e modos de morrer. Ou modos de acolher e modos de recolher.

\section{Referências}

Barbosa, R.P.B., \& Bicalho, P.P.G. (2013). 'Sujeito-Criminoso': mecanismos de produção de subjetividade operantes em policiais em moradores de favelas no Rio de Janeiro, Brasil. Revista Latinoamericana de Psicología Social Ignacio MartinBaró, 2(1), pp.83-110.

Carneiro, H. (2005). Transformações do significado da palavra "droga": das especiarias coloniais ao proibicionismo contemporâneo. In R.P. Venâncio, \& H. Carneiro (Orgs). Álcool e Drogas na História do Brasil. São Paulo: Alameda.

Conrad, P. (2007). The medicalization of society: on the transformation of human conditions into treatable disorders. Baltimore: The J ohns Hopkins University Press.

Conselho Federal de Psicologia [CFP] (2012). Drogas: Direitos Humanos e Laço Social. Brasília: Conselho Federal de Psicologia.

Deleuze, G., \& Guattari, F. (1995). Mil Platôs: Capitalismo e 
esquizofrenia. Vol. I. São Paulo: Editora 34.

Focchi, G. R. de A., Leite, M. da C., \& Scivoletto, S. (2001). Utilização do agonista dopaminérgico pergolida no tratamento da "fissura" por cocaína. Revista Brasileira de Psiquiatria, 23(4), 188-194.

Foucault, M. (1994). Ditos e Escritos IV. (Trad. bras. de Wanderson Flor do Nascimento). Paris: Gallimard.

Hartman, D. M., \& Golub, A. (1999). The social construction of the crack epidemic in the print media. Journal of Psychoactive drugs, 31(4), 423-433.

Hüning, S. M. (2008). O sujeito biotecnológico na viagem pelo reino das batatas transgênicas, porquinhos fosforescentes e almas codificadas. Tese de Doutorado, Pontifícia Universidade Católica do Rio Grande do Sul, Porto Alegre, RS, Brasil.

Latour, B. (1994). Jamais fomos modernos. Rio de Janeiro: Editora 34.

Latour, B. (2000). Ciência em ação: como seguir cientistas e engenheiros sociedade afora. São Paulo: Unesp.

Latour, B. (2008). Reensamblar lo Social: una introduccion a la teoria del actor-red. Buenos Aires: Manantial.

Meyer, M. (2009). From 'cold' science to 'hot' research: the texture of controversy. Papiers de Recherche Du CSI - CSI Working Papiers Series, Paris.

Misse, M. (2007). Mercados ilegais, redes de proteção e organização local do crime no Rio de Janeiro. Estudos Avançados, 21(61), 139157.

Mol, A. (2007). Política ontológica. Algumas idéias e várias perguntas. Nunes, J.A. \& Roque, R. (Org.). Objectos impuros Experiências em estudos sociais da ciência (pp.5-38). Porto: Edições Afrontamento.

Moraes, M. (1998). Uma Psicologia em Ação. Tese de Doutorado, Pontifícia Universidade Católica de São Paulo, São Paulo, SP, Brasil.

Moraes, M. (2004). Science as a network of actors: philosophical resonance. História, Ciências, Saúde-Manguinhos, 11(2), 321333.

Oksala, J. (2011). Como ler Foucault. Rio de Janeiro: Zahar.

Queiroz e Melo, M.F.A. (2008). Mas de onde vem Latour? Pesquisas e Práticas Psicossociais, 2(2), São J oão Del-Rei.

Vargas, E. V. (2008). Fármacos e outros objetos sócio-técnicos: notas para uma genealogia das drogas. I n B. C. Labate, S. L. Goulart, M. Fiore, E. MacRAE, \& H. Carneiro (Orgs.). Drogas e Cultura: novas perspectivas. (pp. 41-64). Salvador: EDUFBA.

\section{Endereço para correspondência}

Alexandre Kerr Pontes

Universidade Federal do Rio de Janeiro 
Campus Praia Vermelha, Programa de Pós-Graduação em Psicologia

Avenida Pasteur, 250, Pavilhão Nilton Campos, CEP 22290-240, Urca, Rio de Janeiro - RJ, Brasil

Endereço eletrônico: akerrp@gmail.com

\section{Ana Paula Santos Meza}

Universidade Federal do Rio de Janeiro

Campus Praia Vermelha, Programa de Pós-Graduação em Psicologia

Avenida Pasteur, 250, Pavilhão Nilton Campos, CEP 22290-240, Urca, Rio de Janeiro - RJ, Brasil

Endereço eletrônico: mezaana@gmail.com

\section{Pedro Paulo Gastalho de Bicalho}

Universidade Federal do Rio de Janeiro

Campus Praia Vermelha, Programa de Pós-Graduação em Psicologia

Avenida Pasteur, 250, Pavilhão Nilton Campos, CEP 22290-240, Urca, Rio de Janeiro - RJ, Brasil

Endereço eletrônico: ppbicalho@ufrj.br

Recebido em: 26/05/2014

Reformulado em: 08/10/2014

Aceito para publicação em: 09/10/2014

\section{Notas}

* Mestre em Psicologia, discente do curso de Doutorado em Psicologia da Universidade Federal do Rio de Janeiro. Bolsista CNPq.

** Mestre em Psicologia, discente do curso de Doutorado em Psicologia da Universidade Federal do Rio de Janeiro. Tenente Psicóloga da Polícia Militar do Estado do Rio de J aneiro.

*** Doutor em Psicologia, Professor Adjunto do Instituto de Psicologia e do Programa de Pós-Graduação em Psicologia da Universidade Federal do Rio de Janeiro. Bolsista de produtividade em pesquisa (CNPq) e Jovem Cientista do Nosso Estado (Faperj).

1 "A expressão caixa-preta é usada em cibernética sempre que uma máquina ou um conjunto de comandos se revela complexo demais. Em seu lugar, é desenhada uma caixinha preta, a respeito da qual não é preciso saber nada, senão o que nela entra e o que dela sai" (Latour citado por Hüning, 2008, p. 16).

http://g1.globo.com/brasil/noticia/2013/01/governo-libera-r-738-milhoes-semconhecer-epidemia-de-crack.html

3 http://noticias.terra.com. br/brasil/internacao-de-adultos-usuarios-de-crack-dorio-nao-encontra-apoio-de-especialistas-do-

setor, 5aa873f2ef6da310VgnCLD200000bbcceb0aRCRD.html 